\section{Poor adherence to long-term treatment of chronic diseases is a worldwide problem}

Around the world, public health efforts to deal with a wide variety of chronic conditions are being undermined by the alarmingly low adherence to therapies, according to a report recently issued by the World Health Organization. Adherence problems are found in all situations where the self-administration of treatment is required, with illnesses that include asthma, hypertension, depression, diabetes, HIV/AIDS, tuberculosis, and dependence on tobacco or other substances. In developed countries, adherence to therapies averages $50 \%$, and the figures are much lower in less developed nations.

"Poor adherence is the primary reason for not achieving the full health benefits medicines can provide to patients," said Dr. Derek Yach, Executive Director, Noncommunicable Diseases and Mental Health, World Health Organization (WHO). "It causes medical and psychosocial complications of disease, reduces patients' quality of life, increases the likelihood of development of drug resistance, and wastes health care resources. Taken together, these direct consequences impair the ability of health care systems around the world to achieve population health goals."

Simplistic approaches to improving the quality of life of persons with chronic conditions are not appropriate, Yach noted in the preface to the new WHO report. Instead, what is needed is a deliberative approach that reviews the way that health professionals are trained and rewarded and that systematically tackles the many barriers that patients encounter as they try to maintain optimal health.

\section{KEY FINDINGS}

The report was developed by studying a wide variety of chronic conditions and risk factors and looking for their commonalities. Lessons gathered from looking at diseases with greater experience on adherence interventions served as a guide to explore many illnesses for which less is known concerning adherence. A number of the report's most important conclusions are described below.

rds: chronic disease, patient professional-patient relations, self administration, treatment outcome.

Based on: (1) World Health Organization. Adherence to long-term therapies. Evidence for action. Geneva: WHO; 2003. (2) World Health Organization. Failure to take prescribed medicine for chronic diseases is a massive, world-wide problem [press release]. Available from: http://www.who.int/mediacentre/releases/2003/pr54/en/. Accessed 7 September 2003
Poor adherence to treatment of chronic diseases is a worldwide problem of striking magnitude

Adherence to long-term therapy for chronic illnesses in developed countries averages $50 \%$. In 
developing countries the rates can be even lower, given the paucity of health resources and the inequities in access to health care. For example, in the United States of America only $51 \%$ of patients adhere to their medication regimen for high blood pressure. In China that figure is $43 \%$, and in Gambia it's just $27 \%$. Similar low rates have been reported for such other illnesses as depression $(40 \%-$ $70 \%$ ), asthma ( $43 \%$ for acute treatments and $28 \%$ for maintenance), and HIV / AIDS (37\%-83\%).

\section{The impact of poor adherence grows as the burden of chronic diseases increases worldwide}

Noncommunicable diseases and mental disorders, HIV/AIDS, and tuberculosis together represented $54 \%$ of the burden of all diseases worldwide in 2001 , and they will exceed $65 \%$ worldwide in 2020. Developed countries are not the only ones dealing with these health problems. In the developing nations of the world, noncommunicable diseases and mental problems represented some $46 \%$ of the total burden of diseases in 2001, and this figure is expected to rise to $56 \%$ by 2020 .

There is a two-way relationship between economic poverty and chronic disease. Being healthy requires money for food and medical care, but to earn money one must be healthy. The lack of adequate care for chronic conditions poses a special burden for poor families caring for loved ones. Women are particularly "taxed" when health care systems do not adequately deal with chronic diseases. Poor adherence to treatment also results in waste and underutilization of already limited health care resources in developing countries.

\section{Better adherence can produce better health outcomes and limit health care expenditures}

Poor adherence to long-term therapies severely compromises the effectiveness of treatment, making this a critical issue in population health both from the perspective of quality of life and of health economics. Good adherence improves the effectiveness of interventions aimed at promoting healthy lifestyles, such as diet modification, increased physical activity, avoiding tobacco use, and practicing safe sexual behavior. Good adherence also makes pharmacological-based interventions more effective. Good adherence, for example, improves blood pressure control and reduces the complications of hypertension. In Sudan only $18 \%$ of nonadherent patients achieved good control of blood pressure, compared to $96 \%$ of patients who adhered to their prescribed treatment. Similarly with type 2 diabetes, studies have found that adherence to a reduced-fat diet and to regular physical exercise has been effective in reducing the onset of the disease. For those already suffering from the disease, good adherence to treatment has helped reduce complications and disability and also improve patients' quality of life and life expectancy.

Higher rates of adherence also provide economic benefits for both health care systems and patients. Better adherence can decrease the need for sophisticated and expensive health care services. Workers who adhere to prescribed treatment are better able to maintain their vocational status. Combining self-management and adherence programs with regular treatment and disease-specific education can reduce the number of outpatient visits as well as the number of persons hospitalized and the number of days they spend in the hospital.

Poor adherence can lead to the development of resistance to therapies. That in turn can produce premature mortality, higher health care costs from morbidity that was not prevented, and the need to invest more for the research and development of new compounds to fight resistant organisms.

\section{Enhancing adherence improves patients' safety}

Patients who do not adhere to prescribed treatment may face a variety of additional risks. For example, relapses related to poor adherence to prescribed medication can be more severe than relapses that happen while the patient is taking the medication as recommended. When medication is abruptly discontinued or interrupted, the patient may suffer harm. Poor adherence can lead to increased resistance to treatment, such as with HIV/AIDS and tuberculosis. Patients who overuse medicines are at risk of increased toxicity. Persons who do not make recommended lifestyle changes when taking some medicines, such as refraining from consuming alcohol, may have a higher likelihood of accidents

\section{Health systems must evolve to meet new challenges}

In developed countries the epidemiological shift in disease burden from acute to chronic diseases over the past 50 years has rendered acute care models of health service delivery inadequate to address the health needs of the population. In developing countries this shift is occurring at a much faster rate. Effectively treating chronic conditions requires moving health care away from focusing on episodic care in response to acute illness to paying 
more attention to proactive care that emphasizes health throughout the lifetime.

The health care delivery system has the potential to affect patients' adherence behavior in a number of ways. Health care systems control access to care through such mechanisms as providers' schedules, length of appointments, allocation of resources, fee structures, communications and information systems, and organizational priorities. For example, with systems that do not reimburse providers for patient counseling and education, there is a serious threat to interventions that focus on adherence. Systems that encourage ongoing communications and engagement with patients, such as through telephone contacts, can improve adherence in a simple, cost-effective way.

\section{Patients need to be supported, not blamed}

There continues to be a tendency to focus on patient-related factors as the causes of problems with adherence, to the relative neglect of provider- and health system-related determinants. Nevertheless, these provider and health system factors can have a major effect on adherence. Making patients solely responsible is misleading and often reflects a lack of understanding of how other factors affect people's behavior and their capacity to adhere to treatment.

\section{Various factors simultaneously influence adherence}

The ability of patients to follow treatment plans in an optimal manner is frequently compromised by such barriers as social and economic factors, the health care team/system, the characteristics of the disease, disease therapies, and patientrelated factors. Solving the problems related to each of these factors is necessary if patients' adherence to therapies is to be improved.

A number of socioeconomic factors and demographic characteristics can influence adherence. These include poor socioeconomic status, poverty, illiteracy, limited education, unemployment, long distance from treatment centers, high cost of transport or medication, and cultural beliefs about illness and treatment. Age can have an impact on adherence at various points in the life cycle. Adolescents, for example, struggle with such issues as self-esteem, body image, and their social role. Poor adherence may be a way for young people to rebel against the treatment regimen's control over their lives. Providing families with information on how parents and adolescents can form a partnership can encourage adherence. Among elderly persons the greater preva- lence of cognitive and functional impairments increases the likelihood of poor adherence.

While a good patient-provider relationship can improve adherence, many health system characteristics can work against that. These include inadequate reimbursement by health insurance plans, poor medication distribution systems, a lack of knowledge and training for providers on how to manage chronic diseases and to improve adherence, short consultations, and a weak system capacity to educate patients and provide follow-up.

Specific condition-related factors can affect adherence. These can include the severity of symptoms, level of disability, and rate of progression of the disease. Comorbidities, such as depression or drug or alcohol abuse, can hinder adherence.

Also influencing adherence are therapyrelated factors. Among these are the complexity of the medical regimen, duration of treatment, immediacy of beneficial effects, level of side effects, and availability of medical support.

The resources, knowledge, attitudes, beliefs, and expectations of patients will have an impact. Providers can improve adherence by boosting patients' motivation by emphasizing the importance of adherence and by helping them build their selfmanagement skills.

\section{Patient-tailored interventions are necessary}

There is no single intervention strategy or package of strategies that has been shown to be effective across all patients, conditions, and settings. Therefore, interventions that target adherence must be tailored to the particular illness-related demands experienced by the patient. To accomplish this, health systems and providers need to develop means of accurately assessing both adherence and the factors that influence adherence.

\section{Adherence is a dynamic process that health care providers need to monitor}

Improving adherence requires a continuous and dynamic process. Research in the behavioral sciences has shown that patients can be categorized according to their level of readiness to follow health recommendations. Mismatches between patients' readiness and practitioners' attempts at intervention mean that treatments are frequently prescribed to patients who are not ready to follow them. Health care providers should be able to assess a patient's readiness to adhere, provide advice on how to do it, and follow up the patient's progress at every contact. 


\section{Health professionals should be trained in adherence}

Health providers can have a noticeable impact by assessing risk of nonadherence and delivering interventions to optimize adherence. To make this practice a reality, practitioners must have access to specific training in adherence management, and the systems in which they work must design and support delivery systems that respect this objective. The training needs to simultaneously address three topics: knowledge (information on factors that affect adherence), thinking (clinical tools to assess patient adherence and to choose the best available intervention), and action (behavioral tools for creating and maintaining habits in patients).

\section{The family, the community, and patients' organizations are key to improving adherence}

For the effective provision of care for chronic conditions, it is necessary that the patient, the family, and the community who support him or her all play an active role. Informal or formal support that patients receive from their peers and from other members of their community can improve adherence to therapy while reducing the amount of time that health professionals must devote to caring for chronic conditions.

\section{A multidisciplinary approach towards adherence is needed}

Even though there is an extensive knowledge base on adherence, efforts to address the problem have been fragmented and have seldom harnessed the potential contributions of various health disciplines. A stronger commitment to a multidisciplinary approach is needed to make progress in this area. This will require coordinated action from health professionals, researchers, health planners, and policymakers.

A copy of the complete WHO report in PDF format can be printed out or downloaded for free from the WHO Web site at: http://www.who.int/ chronic_conditions/adherencereport/en/. Printed copies of the report can be purchased through WHO sales agents in many countries around the world, and copies can also be ordered on the Internet (http://bookorders.who.int) or from WHO Marketing and Dissemination, 1211 Geneva 27, Switzerland. The cost is US $\$ 13.50$ for persons in developing nations and US\$27.00 elsewhere.

\section{SINOPSIS}

\section{El incumplimiento de los tratamientos prolongados de las enfermedades crónicas es un problema mundial}

En el mundo, los esfuerzos de las instituciones sanitarias para controlar una amplia gama de enfermedades crónicas se ven frustrados por el alarmante incumplimiento de los tratamientos prescritos, según un reciente informe emitido por la Organización Mundial de la Salud (OMS), resumido en este artículo. Los problemas con el cumplimiento de los tratamientos se encuentran siempre que estos deban ser administrados por el propio paciente para combatir enfermedades tales como el asma, la hipertensión arterial, la depresión, la diabetes, la infección por VIH/sida, la tuberculosis y la dependencia del tabaco $u$ otras sustancias. En los países desarrollados, el cumplimiento de los tratamientos es de $50 \%$ en promedio y el problema es mucho mayor en países de menor desarrollo. El incumplimiento de los tratamientos explica por qué los pacientes no siempre logran obtener todos los beneficios que ofrecen los medicamentos. Además, genera complicaciones médicas y psicosociales, afecta a la calidad de la vida de los pacientes, incrementa la posibilidad de desarrollar resistencia a los medicamentos y malgasta los recursos sanitarios. Los enfoques simplistas para el mejoramiento de la calidad de la vida de las personas con enfermedades crónicas no son los adecuados. Más bien, se necesita un enfoque que revise la forma en que los profesionales de la salud son entrenados y remunerados y que aborde sistemáticamente las numerosas barreras que encuentran los pacientes y sus familiares para mantener un estado óptimo de salud. El informe de la OMS entrañó el análisis de una amplia gama de enfermedades crónicas y factores de riesgo en busca de elementos comunes. Las lecciones derivadas de aquellas enfermedades en las que las intervenciones para el cumplimiento de los tratamientos han logrado mejores resultados sirvieron de guía para la prospección de muchas otras enfermedades en las que este problema es menos conocido. 